\title{
Does size really matter? Effects of fish surface area on the settlement and initial survival of Lepeophtheirus salmonis, an ectoparasite of Atlantic salmon Salmo salar
}

\author{
C. S. Tucker*, C. Sommerville, R. Wootten \\ Institute of Aquaculture, University of Stirling, Stirling FK9 4LA, Scotland, UK
}

\begin{abstract}
The effect of the size of the surface area of a fish host on settlement and initial survival of Lepeophtheirus salmonis (Krøyer, 1837) was determined. Atlantic salmon Salmo salar L. of various sizes - small $(43 \pm 4 \mathrm{~g})$, medium $(173 \pm 32 \mathrm{~g})$ and large $(644 \pm 62 \mathrm{~g})$ - were initially examined to ascertain their respective body surface area, excluding gill surface. The initial examination showed a sizedependent body to fin area ratio, with the fin area of small fish representing $34 \%$ of the total body area and the fin area of medium and large fish representing 26 and $23 \%$, respectively. Regression analysis of the body weight and standard length against total body surface area gave a good correlation and high $\mathrm{R}^{2}$ values. Two simultaneous experimental infections with approximately 7000 copepodids of L. salmonis were carried out on fish populations of mixed sizes consisting of 30 small fish, 10 medium-sized fish and 5 large fish, with an approximate total surface area per size group of $2700 \mathrm{~cm}^{2}$. Higher numbers of parasites were found on the small size group, which also had the highest parasite density, with 0.25 and 0.45 parasites $\mathrm{cm}^{-2}$. Comparison of samples of 5 fish per experimental group revealed that the larger fish had the highest mean numbers of parasites, but the smaller fish still retained the highest density. There was a statistically significantly higher settlement on the fins than on the remainder of the body surface in all size groups. Highest numbers of parasites were particularly found on the dorsal and pectoral fins. Examination of the surface surface area revealed that the dorsal fin had the greater parasite density, with $>2$ parasites $\mathrm{cm}^{-2}$ in all fish size groups. These data provide insight into the effects of the amount of host surface area available on parasite settlement and survival, and highlight the potentially increased susceptibility of farmed salmon smolts to infection of this ectoparasite.
\end{abstract}

KEY WORDS: Lepeophtheirus salmonis $\cdot$ Sea lice $\cdot$ Surface area $\cdot$ Settlement

Resale or republication not permitted without written consent of the publisher

\section{INTRODUCTION}

The size of the available surface area of a potential host will have a marked effect on the numbers of ectoparasites it can support and on any resulting pathology. In most published parasitological studies the terms 'intensity', 'prevalence' and 'abundance' (Mar-

*Present address: National Research Institute of Fisheries Science, 2-12-4 Fukuura, Kanazawa-ku, Yokohama 2368648, Japan.E-mail: carl@affrc.go.jp golis et al. 1982) are used to quantitatively describe parasite burdens. However, 'density', defined as 'number of individuals of a particular parasite species per unit area, volume or weight of infected host tissue or organ' (Margolis et al. 1982), may be a better measure of the level of infection, particularly for the assessment of the pathogenic potential of ectoparasites, and in mixed year-classes of fish.

Larger fish are potentially better able to withstand an infection of a given concentration than smaller fish infected with the same number of ectoparasites. 
Generally, parasitic infections show an increase in infection intensity with an increase in host size, due to the larger surface area available for attachment (Dogiel et al. 1958), e.g. Hanek \& Fernando (1978) clearly demonstrated an increased intensity of infection with Monogenea and Copepoda with increasing age and size of Lepomis gibbosus. On the other hand, the parasitic copepod Lernaeenicus sprattae did not demonstrate a host-size preference (Anstenrud \& Schram 1988). While absolute numbers of ectoparasites may be higher in larger fish, parasite density can decrease with age, and thus pathogenic effects could be more severe in apparently more lightly infected but smaller fish.

The caligid copepod Lepeophtheirus salmonis (Krøyer, 1857) is a highly pathogenic ectoparasite of salmonids, particularly in culture, causing significant economic loss. Smaller fish tend to be most susceptible to damage caused by the parasite even though they harbour lower absolute numbers of L. salmonis. An understanding of the density of parasites on fish of different sizes may be helpful in assessing potential pathogenicity and in developing control strategies. Jaworski \& Holm (1992) described the distribution of pre-adult and adult L. salmonis on the surface of Atlantic salmon using parasite density. These authors reported that larger fish have higher parasite intensities due to the increased surface area available, and that when fish of various sizes are considered, surface area more reliably reflects lice intensity than percentage of parasites. Further, they suggested 2 methods of describing the parasite distribution on the host. Firstly, as the number of lice in each body region expressed as a proportion (or percentage) of the total number of lice on the fish, or secondly as the infestation in each body region expressed as a ratio of the local parasite intensity to the average for the whole fish body. Both methods express parasites in terms of numbers per unit area $\left(\mathrm{cm}^{2}\right)$.

Jaworski \& Holm (1992) devised a method of expressing the intensity of motile Lepeophtheirus salmonis stages on fish of different sizes with a surface-area model that calculates parasite density in 8 specified regions. Their methodology divides the host into regions that combine body-surface area with finsurface area. Tucker et al. $(2000 \mathrm{a}, \mathrm{b})$ demonstrated the preferential pattern of $L$. salmonis settlement on the fins, thereby suggesting that the methodology of Jaworski \& Holm (1992) required refinement, particularly when whole populations of L. Salmonis, with all life stages present, are considered. Given that copepodids of L. salmonis show a preferential settlement on the fins of fish, it is of interest to consider parasite density at these sites and how it relates to total burden. Grimnes \& Jakobsen (1996) proposed that lice infection intensities of $>30$ larvae on post-smolt salmon would ultimately result in severe damage to the host and contribute to the death of the fish through the lesions generated and the resultant osmoregulatory failure and secondary infection. The aim of this study was the establishment of a system of assessing infestation densities of L. salmonis on Atlantic salmon Salmo salar L. by examining the effects of the size of fish surface area on the settlement and subsequent initial survival of the infective copepodids.

\section{MATERIALS AND METHODS}

Measurement of fish surface area. To calculate fish surface area, 72 apparently healthy salmon of varying sizes were processed individually to estimate the individual fin and the total body surface areas. All fins were dissected from the fish, after which fins and bodies were laid out and photographed to allow tracing of the surface area to scale by computer-linked image-analysis VIDAS v2.1 and Videoplan (Imaging Associates). All measurements were taken 3 times to provide a mean value. Exponential and linear regression equations of surface area against fish length and weight were derived to allow an estimation of the total surface area of a fish from its length and weight. Since weight gave a marginally better correlation, this parameter was used to approximate the fish surface area and, therefore, the number of fish to be used in the experimental infection study. Gill-surface area was not examined.

Experimental parasite infections with Lepeophtheirus salmonis. Gravid L. salmonis were collected from Atlantic salmon at a single naturally infected farm site. Their ovisacs were incubated in a static system at ambient seawater temperatures $\left(8.6 \pm 0.5^{\circ} \mathrm{C}\right)$ and salinity $(35 \%)$. Hatched nauplii stages were cultured, under the same experimental conditions, to the copepodid stage. Each day, $75 \%$ of the seawater was changed, and dead or moribund adult lice were removed to ensure optimum water conditions. The development of L. salmonis larvae was examined daily, and approximately the first 7000 reaching the copepodid stage were used for the experimental infection. These copepods were used within $12 \mathrm{~h}$ after moulting from the Nauplius II stage.

Prior to infection, the approximate surface areas of 10 large fish (mean $644.4 \pm 61.6 \mathrm{~g}$ ), 20 medium-sized fish (mean $172.9 \pm 31.8 \mathrm{~g}$ ), and $60 \mathrm{small}$ fish (mean 42.8 $\pm 4.1 \mathrm{~g}$ ) were calculated and found to have a total surface area of $\sim 2800, \sim 2600$ and $\sim 2800 \mathrm{~cm}^{2}$, respectively. These experimental fish were divided equally but (within each size group) randomly into two 7361 tanks. Both tanks, of 45 fish each, were simultaneously infected with Lepeophtheirus salmonis at an approxi- 
mate copepodid concentration of 10 copepodids $\mathrm{l}^{-1}$. The experimental infection process lasted $8 \mathrm{~h}$, during which time the water supply was stopped. Tanks were aerated throughout the infection period to ensure sufficient oxygenation for the survival of the fish and to increase the homogeneous mixing of the copepodids throughout the water column. All fish were examined under anaesthetic (MS222 at 100 ppm) at 5 and $10 \mathrm{~d}$ post-infection (dpi), at which times lice stages, position and numbers were recorded, to determine settlement and initial survival, respectively.

Statistical analysis. Statistical analysis of each experiment was conducted separately to reveal any trends. Numerical data for settlement and survival on each experiment were analysed using the KruskalWallis non-parametric test, after testing for data homogeneity of variances and normality (Sokal \& Rohlf 1981). Further statistical analysis of the numerical differences in parasite numbers and density between body regions in each experiment was conducted using either Dunn's multiple-comparison non-parametric test or by calculating the $95 \%$ confidence interval for proportions and percentages according to Fowler \& Cohen (1992).

\section{RESULTS}

\section{Fish surface area}

The average surface area of different body regions $\left(\mathrm{cm}^{2}\right)$ for each size group of fish, calculated from imageanalysis, is given in Table 1. Body-surface values will be underestimated as the image-analysis process can only measure the surface area of a 2D, not a 3D image.

Fin area as a percentage of total surface area was significantly greater $(p<0.05)$ in the small fish $(33 \%)$ than in the 2 larger size groups. In all groups, the caudal fin had the greatest surface area, followed by the pectoral fins. The caudal fin was significantly larger and the adipose fin significantly smaller than all other fins in each size group ( $p<0.01)$. Furthermore, and only within the small fish group, the pectoral fin was statistically larger than the pelvic and anal fins which, in turn, were larger than the dorsal fin $(p<0.05)$.

\section{Regression analysis of fish length and weight on surface area}

From the determined host surface area, a regression analysis against weight and standard length was conducted. Results of the linear and exponential regression analysis of Atlantic salmon total body-surface area (excluding gills) on weight and standard length are given in Figs. 1 \& 2 .

Linear regression analysis of fish weight on total surface area (Fig. 1) gives the regression equation: $y=$ $0.6131 x+86.144$, with an $\mathrm{R}^{2}$ value of 0.9871 , whilst exponential regression analysis gives the equation $y=$ $111.48 \mathrm{e}^{0.0021 x}$, with an $\mathrm{R}^{2}$ value of 0.9467 . Linear regression analysis of fish standard length with total surface area (Fig. 2) gives the regression equation: $y=$ $1.3311 x-74.035$, with an $\mathrm{R}^{2}$ value of 0.9267 , whilst exponential regression analysis gives the equation $y=$ $54.66 \mathrm{e}^{0.0056 x}$, with an $\mathrm{R}^{2}$ value of 0.963 .

\section{Effects of size of host surface area on copepodid settlement (5 dpi) and survival (10 dpi)}

Settlement was examined in 2 ways, initially as the copepodid density for the whole population of fish in each tank, and then as the copepodid density for an equal number of fish from different size groups to allow examination of effects at an individual size level. Each experiment (Table 2) was examined and analysed separately.

Table 1. Salmo salar. Average fish surface area $\left(\mathrm{cm}^{2}\right)$, and percentage of total surface area of various body regions for different size classes

\begin{tabular}{|lcccccccc|}
\hline $\begin{array}{l}\text { Fish } \\
\text { size }\end{array}$ & Body & $\begin{array}{c}\text { Pectoral } \\
\text { fin }\end{array}$ & $\begin{array}{c}\text { Pelvic } \\
\text { fin }\end{array}$ & $\begin{array}{c}\text { Anal } \\
\text { fin }\end{array}$ & $\begin{array}{c}\text { Caudal } \\
\text { fin }\end{array}$ & $\begin{array}{c}\text { Adipose } \\
\text { fin }\end{array}$ & $\begin{array}{c}\text { Dorsal } \\
\text { fin }\end{array}$ & $\begin{array}{c}\text { Total fin } \\
\text { area }^{2}\end{array}$ \\
\hline Small & & & & & & & $\begin{array}{c}\text { Total } \\
\mathrm{cm}^{2}\end{array}$ \\
$(\sim 43 \mathrm{~g})$ & 64.24 & 9.79 & 6.21 & 2.47 & 11.78 & 0.46 & 1.84 & 32.55 \\
& $66.37 \%$ & $10.12 \%$ & $6.42 \%$ & $2.55 \%$ & $12.17 \%$ & $0.47 \%$ & $1.90 \%$ & $33.63 \%$ \\
Medium & & & & & & & \\
$(\sim 173 \mathrm{~g})$ & 177.76 & 13.45 & 11.69 & 5.34 & 24.46 & 0.86 & 7.36 & 63.16 \\
& $73.78 \%$ & $5.58 \%$ & $4.85 \%$ & $2.22 \%$ & $10.15 \%$ & $0.36 \%$ & $3.06 \%$ & $26.22 \%$ \\
Large & & & & & & & 240.93 \\
$(\sim 644 \mathrm{~g})$ & 433.67 & 32.92 & 25.08 & 12.95 & 43.45 & 2.29 & 13.05 & 129.74 \\
& $76.97 \%$ & $5.84 \%$ & $4.45 \%$ & $2.30 \%$ & $7.71 \%$ & $0.41 \%$ & $2.32 \%$ & $23.03 \%$ \\
\hline
\end{tabular}




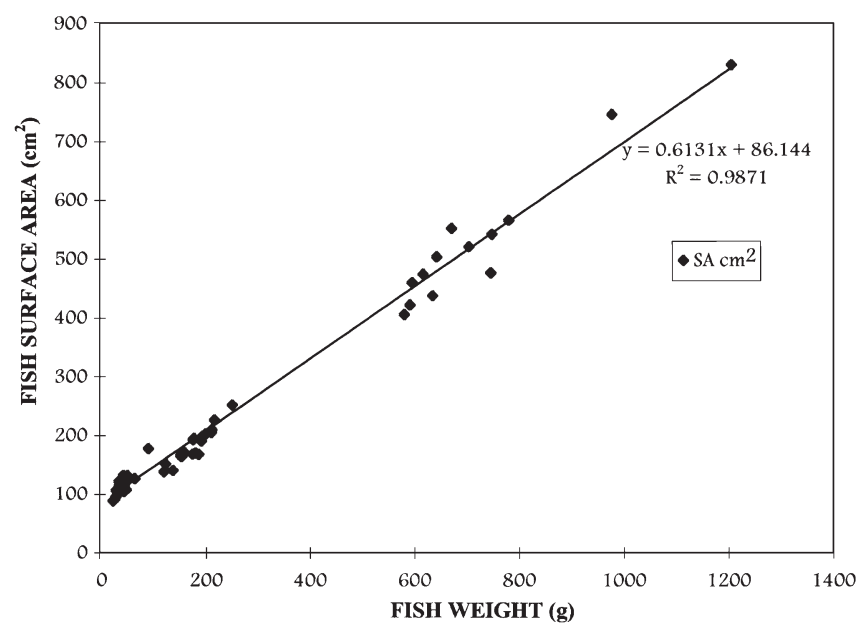

Fig. 1. Salmo salar. Regression analysis of Atlantic salmon weight on total body surface area (SA), excluding gill area $(\mathrm{n}=72)$

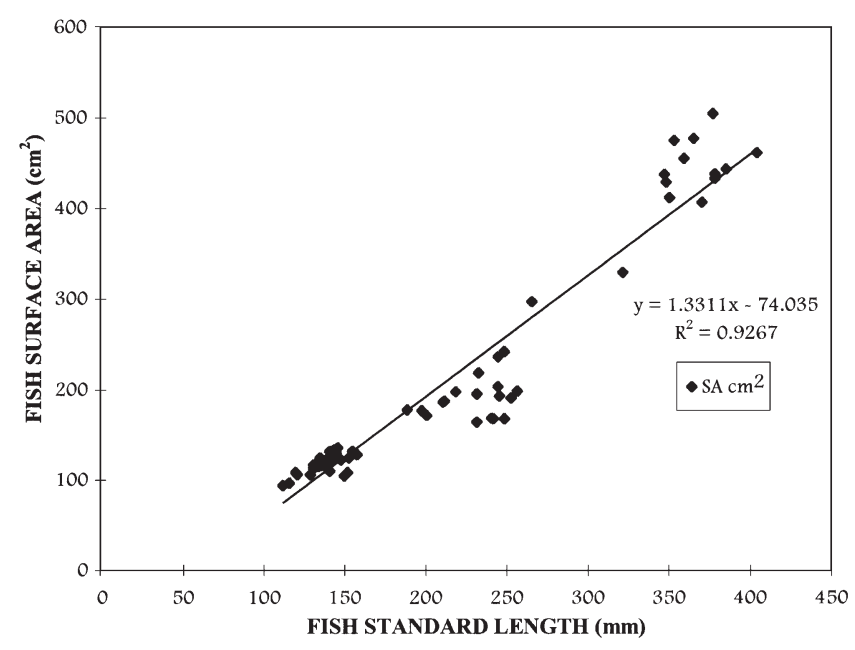

Fig. 2. Salmo salar. Regression analysis of Atlantic salmon standard length on total body surface area (SA) excluding gill area $(\mathrm{n}=72)$

The percentage settlement and survival of copepodids and parasite density on hosts of varying sizes is shown in Fig. 3. In Expt 1 (Fig. 3a) there was a statistically greater parasite density $(\mathrm{p}<0.05)$ in the small fish than in the larger fish, whilst in Expt 2 (Fig. 3b) there was a significantly greater parasite density $(p<0.05)$ in the small fish compared to the other 2 size groups. In the small fish groups, settlement was 0.25 and 0.45 parasites $\mathrm{cm}^{-2}$ for Expts 1 and 2, respectively. Percentage settlement was 9,7 and $5 \%$ for small, medium and large fish, respectively, in Expt 1, whilst in Expt 2 these values were 17, 14 and $15 \%$ (Table 2). Overall, within the total population of fish settlement numbers of copepodids were highest in the small fish groups.
Fig. 4 presents the settlement of Lepeophtheirus salmonis on 5 randomly selected fish from each of the experimental size groups for both tanks. The large fish groups show higher settlement counts in both experiments that is statistically higher $(p<0.05)$ than for other fish groups. However, comparison of the parasite density of the same 5 fish shows a significantly higher density on the smaller fish $(p<0.05)$ than on the other 2 size groups. Thus, in these experiments there was an inverse relationship between parasite density and fish size, whilst absolute parasite numbers were relative to fish size.

Examination of the Lepeophtheirus salmonis initial survival data (Table 2) showed that in Expt 1 there was a significantly greater survival $(\mathrm{p}<0.05)$ at $10 \mathrm{dpi}$ in the small fish than in the larger size groups, whilst in Expt 2 there was a significantly greater survival in the medium fish group than in the small and large size groups. In Expt 1 survival was $>90 \%$, whilst in Expt 2 survival in the small size group was $~ 70 \%$ compared to $>80 \%$ in the large and $>90 \%$ in the medium size group.
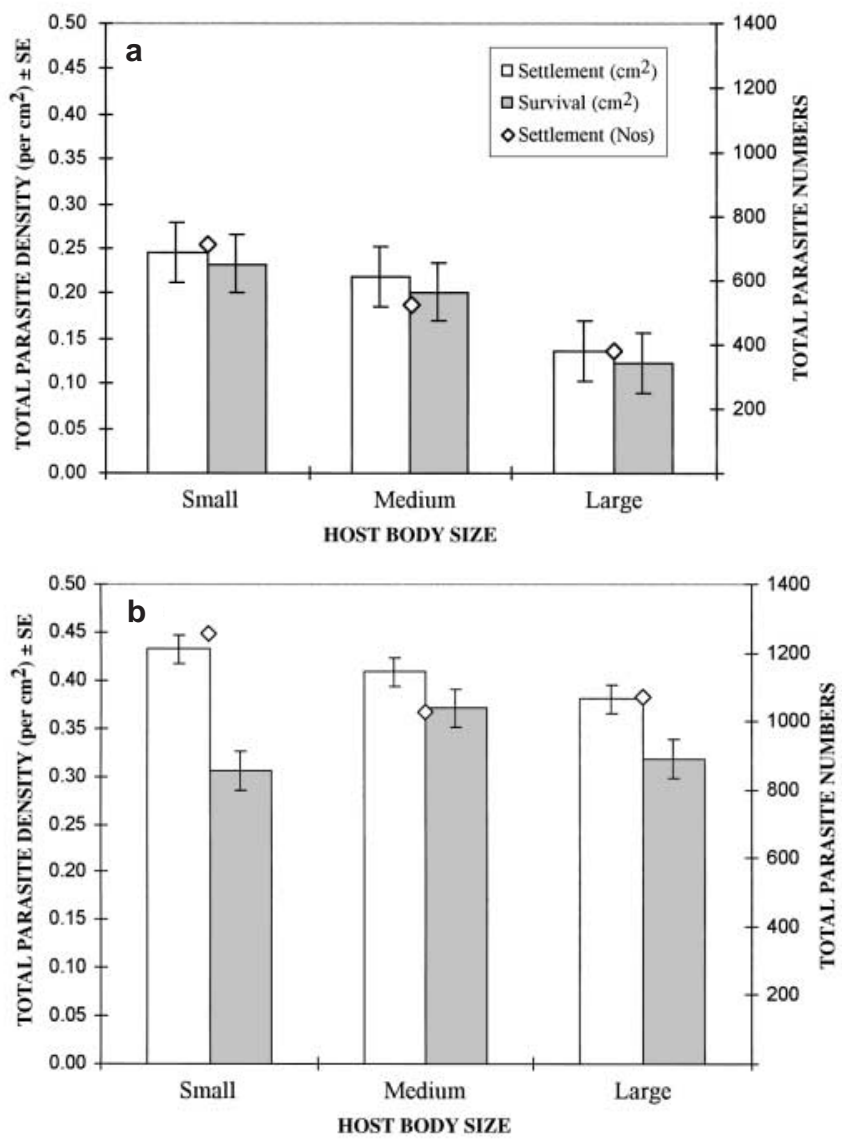

Fig. 3. Salmo salar. Effect of host surface area (fish of 3 size groups) on copepodid total settlement ( $5 \mathrm{~d}$ post-infection, dpi) and initial survival (10 dpi) on the total population of fish (S. salar). (a) Expt 1; (b) Expt 2 
Table 2. Lepeophtheirus salmonis. Percentage settlement and percentage survival of copepodids infecting Atlantic salmon Salmo salar of differing surface areas. Small $=30$ small fish (avg. wt 43 g); Medium $=10$ medium fish (avg. wt $173 \mathrm{~g}) ;$ Large = 5 large fish (avg. wt $644 \mathrm{~g})$

\begin{tabular}{|c|c|c|c|c|c|c|}
\hline \multirow[t]{2}{*}{ Expt } & \multicolumn{3}{|c|}{ Settlement } & \multicolumn{3}{|c|}{ Survival } \\
\hline & Small & Medium & Large & Small & Medium & Large \\
\hline 1 & 9.30 & 6.88 & 4.97 & 94.54 & 92.05 & 90.58 \\
\hline 2 & 17.04 & 13.94 & 14.55 & 70.81 & 90.74 & 83.75 \\
\hline
\end{tabular}

Table 3. Lepeophtheirus salmonis. Total copepodid settlement on the body surface, gills and fins of Atlantic salmon Salmo salar of different sizes expressed as percentage settlement

\begin{tabular}{|c|c|c|c|}
\hline Size class & Body & Gills & Fins \\
\hline \multicolumn{4}{|l|}{ Expt 1} \\
\hline Small & $19.75 \pm 1.12$ & $13.17 \pm 0.34$ & $67.09 \pm 1.31$ \\
\hline Medium & $10.98 \pm 1.27$ & $13.83 \pm 1.01$ & $75.19 \pm 4.77$ \\
\hline Large & $15.18 \pm 0.44$ & $17.28 \pm 0.75$ & $67.54 \pm 5.27$ \\
\hline \multicolumn{4}{|l|}{ Expt 2} \\
\hline Small & $24.64 \pm 0.42$ & $9.09 \pm 0.34$ & $66.27 \pm 1.13$ \\
\hline Medium & $17.25 \pm 2.11$ & $11.01 \pm 1.19$ & $71.73 \pm 3.46$ \\
\hline Large & $23.91 \pm 0.70$ & $7.47 \pm 0.53$ & $68.63 \pm 1.88$ \\
\hline
\end{tabular}

\section{Effects of size of host surface area on copepodid settlement distribution}

The percentage settlement on the fins, gills and body of the salmon is shown in Table 3, which reveals the fins to be the major site of settlement, with $>65 \%$ settlement in both experiments in all fish size groups. Within the various fin and body regions (Fig. 5) the density of parasites was highest, in both experiments,

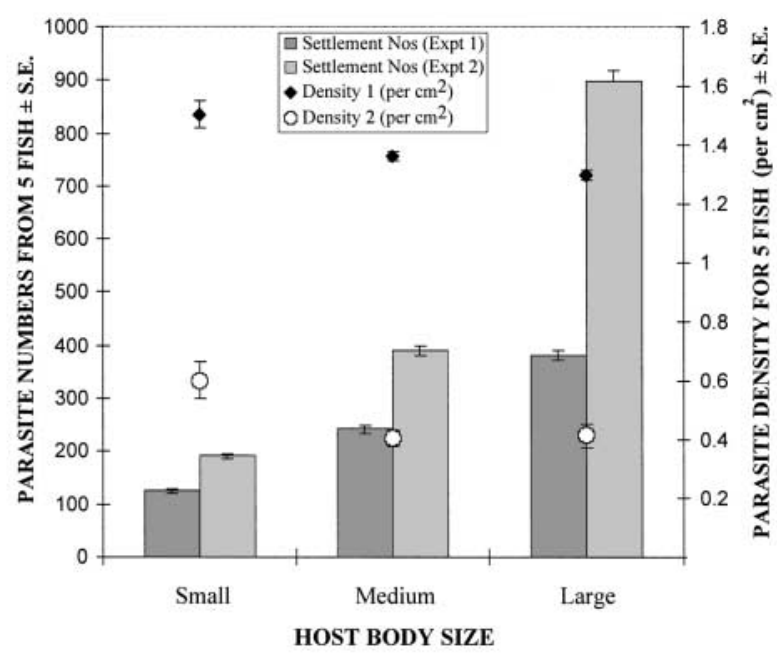

Fig. 4. Salmo salar. Effect of host surface area on copepodid settlement (5 dpi) following examination of 5 fish (Salmo salar) per experimental group on the dorsal fin: $>2.0$ parasites $\mathrm{cm}^{-2}$ in Expt 1 and 3.5 parasites $\mathrm{cm}^{-2}$ in Expt 2 in all size groups of fish. Examination of all fins within each fish size group showed that for the small and medium-sized fish groups settlement was statistically higher $(\mathrm{p}<0.05)$ on the dorsal fin in both experiments. In the large size group, such statistically higher settlement was only found in Expt 1 (Fig. 5a) between the body and the dorsal fin and between the caudal fin and the dorsal fin, whilst in Expt 2 (Fig. 5b) settlement was statistically higher between the body and the adipose fin, between the body and the dorsal fin, and between the caudal fin and the dorsal fin.

No significant difference $(p>0.05)$ was found between the fish size groups in settlement density on the dorsal fin or within the other specific fin groups, except for the adipose fin in Expt 1. Here a significantly lower settlement (95\% CI) was found in the large size group compared with the other groups. Although parasite density was high on the adipose fin, total parasite numbers were low because of the small surface area of this fin (Table 1).

\section{DISCUSSION}

As far as the authors are aware, this is the first study to examine the surface area of fins as well as the area of the body surface in association with parasite burdens. It should be noted that a limitation of the present image-analysis methodology is that the area of the body surface is calculated from a $2 \mathrm{D}$ image. As the body surface is curved this results in a slight underestimate of the body surface area; however, a 3D mathematical prolate ellipsoid model is under development to resolve this problem. As the fins were dissected free of the body and measured flat, imageanalysis provides an accurate method of assessing their surface area. To confirm the accuracy of the image-analysis method, dissected fins were laid out on acetate sheets and their outline traced; an estimate of the fin surface area was then made by laying the acetate on graph paper. The estimate obtained by this method showed good agreement with estimates for the same fins by image analysis (data not shown). Regression analysis of the calculated surface area against fish weight and standard length showed that weight gave a better correlation and this parameter was therefore 

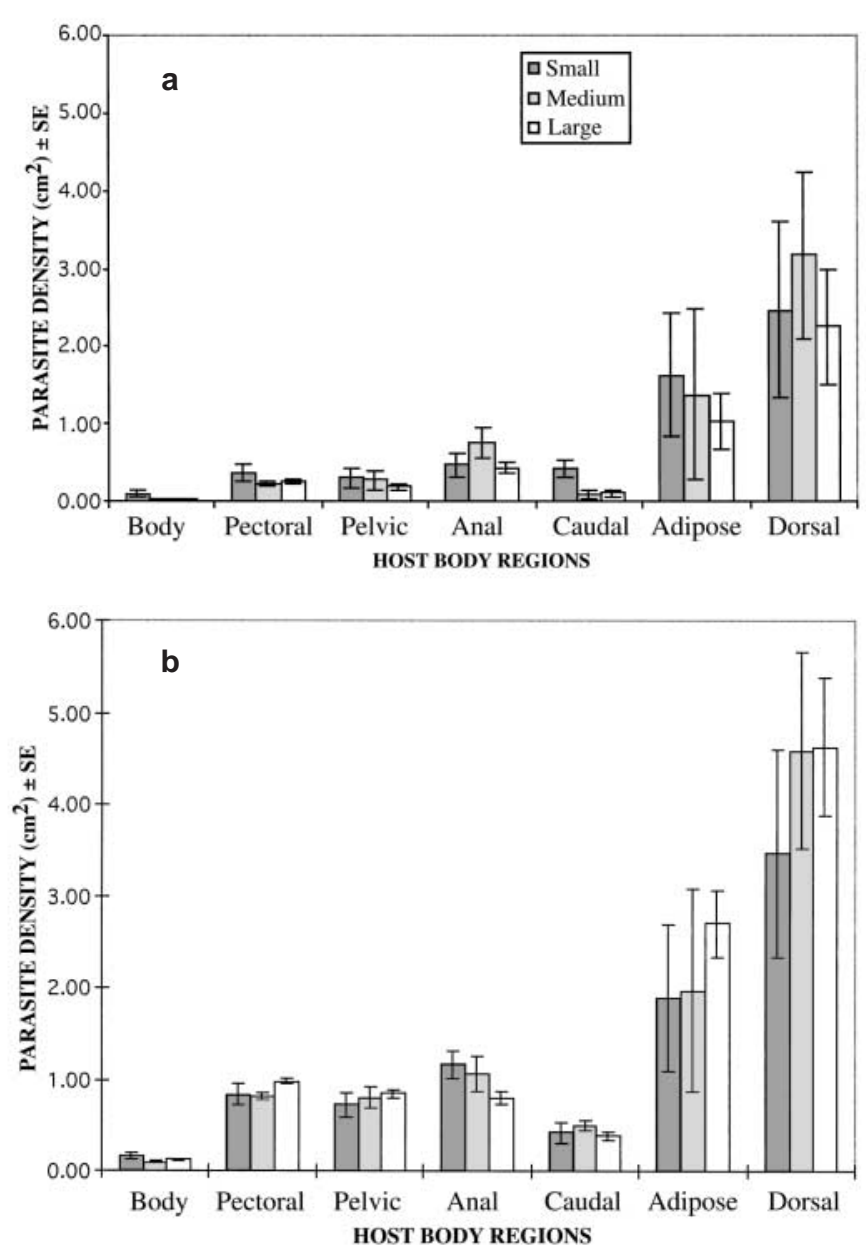

Fig. 5. Salmo salar. Total copepodid settlement on the body surface and the fins of Atlantic salmon Salmo salar of different size groups expressed as parasite density. (a) Expt 1; (b) Expt 2

used in the calculation and approximation of the surface areas and, therefore, the number of fish used in the experimental groups. Jaworski \& Holm (1992) obtained similar $\mathrm{R}^{2}$ values for correlations of weight and length in Atlantic salmon.

Both experimental tanks of fish were infected on the same day and under the same conditions, and yet there was a large difference between them in the number of parasites settling, i.e. 1624 parasites compared to 3351 parasites for Expts 1 and 2, respectively. The seawater temperature at the time of infection may have influenced the overall low settlement of $<17 \%$ (Tucker et al. 2000a); however, the reasons for the variability in numbers settling and surviving between the 2 tanks is as yet unclear. This could be related to unobserved fish behaviour; however, such variability is not uncommon in infection experiments (Tucker 1998). In this study initial survival of Lepeophtheirus salmonis to $10 \mathrm{dpi}$ (Table 2, Fig. 3) was high $(>70 \%$ ) in all fish size groups, and if this translates into corresponding numbers of pre-adult and adult stages it would have a significant impact on the survival of the host (Grimnes \& Jakobson 1996).

The results of the present experiments (Fig. 4) show that, not surprisingly, higher absolute numbers of lice occur on the largest fish, as also reported by Jaworski \& Holm (1992) and in agreement with data of Dogiel et al. (1958) and Hanek \& Fernando (1978). However, such data are of limited value when comparing different year classes of fish or mixed populations of fish. When the infection level is expressed as density (Figs. $3 \& 4$ ), i.e. the number of parasites per $\mathrm{cm}^{2}$, then it can be seen that the heaviest intensities occur in the smallest fish, even though all size groups of salmon were simultaneously infected under the same conditions. The significance of parasite burden on smallsized fish may not be obvious from parasite counts alone.

The greater intensity of settlement on the smallest fish may reflect the greater surface area of the fins relative to the total body surface area (33\%) in this group compared with the medium and large fish, in which fin area was 26 and $23 \%$ of the total area, respectively (Table 1). Over $65 \%$ of total settlement occurred on the fins in all size groups of fish, and thus the greater relative fin surface area of the smallest fish will lead to a greater number of parasites per $\mathrm{cm}^{2}$ of overall body surface (Table 3, Fig. 5). Other authors (Wootten et al. 1982, Johnson \& Albright 1992) have described the preferential attachment of chalimus larvae of Lepeophtheirus salmonis to the fins, and Tucker et al. $(2000 a, b)$ showed a settlement preference for the pectoral and dorsal fins. In this study, the dorsal fin had a higher parasite density than the pectoral and most other fins, despite its relatively small comparative surface area (Table 1). It should be noted that the paired pectoral fins have the second largest surface area, following that of the caudal fin (Table 1).

Boxshall (1976) suggests that preferential fin settlement by Lepeophtheirus pectoralis is due to these sites being associated with water currents and that copepodids move towards water currents. As such, settlement distribution reflects the attraction of water currents produced by the host and particularly the fins of a fish, which are dynamic zones of flow, pressure distribution and thrust (Bone et al. 1995, Bond 1996). Fins, with their fin rays, may also provide increased protection as microhabitats for settlement. Such preferential microhabitat settlement was proposed by Crisp (1961) after determining that barnacle cyprids will actively seek hemispherical pits on presented substrates for attachment.

The exact mechanism for detection of the host by sea lice is unknown. Gresty et al. (1993) and Laverack \& 
Hull (1993) suggested initial host detection by means of mechanoreception setae on the copepodid antennules, after which contact chemoreception is utilized. Bron et al. (1991) similarly proposed that copepodid attraction to a fish is stimulated by rheotaxis and therefore other factors (e.g. size-related swimming speed) may play an important part in the higher parasite density found in smaller fish. Jobling (1995) suggested optimum swimming speeds of 1 to 3 body lengths $\mathrm{s}^{-1}$ for large fish, which move more rapidly in absolute terms than smaller fish, thus making it more difficult for a copepodid to successfully make contact. Copepodid stimulated swimming speed has been measured at $6.84 \mathrm{~cm} \mathrm{~s}^{-1}$ (Gravil 1996); this is considerably slower than the potential swimming speeds of the fish used in this study (139 to $379 \mathrm{~cm}$ standard length).

Gill settlement is considered to be an experimental artefact (Tucker et al. 2000a) and has not been considered further in these experiments. Bron et al. (1991) reported gill settlement on experimentally infected Atlantic salmon and also concluded this to be an artefact of experimental conditions. However, it has been reported, by Johnson \& Albright (1991) that in their experiments the majority of Lepeophtheirus salmonis copepodids did settle on the host gills.

The model for lice infection densities proposed by Jaworski \& Holm (1992), although it does not allow for the differentiation of fin surfaces from body surfaces, generally works well for the motile pre-adult and adult stages of the parasite that are mostly found on the anterior and dorsal body surfaces of the fish. Larger fish with a greater surface area carry higher densities of these stages of the parasite, which are themselves relatively large and occupy more of the surface area of the fish. Pre-adult and adult lice are known to migrate to specific regions on the host, specifically the head, rear of the dorsal fin and the vent being favoured (Wootten et al. 1982).

Based on the data of Jaworski \& Holm (1992), it might be expected that there would be a loss of motile stages from smaller fish because of their low overall carrying capacity on the body surface for larger parasites. Given that the great majority of chalimus settle on the fins, which constitute a relatively small surface area, it would also be of interest to study whether there are any density-dependent effects on establishment and survival through the chalimus stages of Lepeophtheirus salmonis.

This could be important in determining the ultimate pathological effects of an infection. Small fish will tolerate a much smaller number of motile stages because of their lower overall body surface area. As salmon post-smolts are very susceptible to sea lice infections due to their relatively slower swimming speed, greater fin surface area, and thinner epithelium, it is conse- quently important that parasite burdens be assessed at as early a stage of development as possible before severe pathology results. In practical terms this study suggests that monitoring of the dorsal and pectoral fins alone will provide a good indication of lice settlement and early development. Additionally, we have highlighted the requirement to carefully monitor newly introduced post-smolts for such parasitic burdens in a culture environment.

Acknowledgements. Special thanks must go to Dr. Bill Roy and his staff at the Marine Environmental Research Laboratory, Machrihanish, for the provision of additional salmon for the surface area analysis and for their help and support. This study was undertaken with the financial support of the Biotechnology and Biological Sciences Research Council (BBSRC).

\section{LITERATURE CITED}

Anstensrud M, Schram TA (1988) Host and site selection by larval stages and adults of the parasitic copepod Lernaeenicus sprattae (Sowerby) (Copepoda: Pennellidae) in the Oslofjord. Hydrobiologia 167/168:587-595

Bond CE (1996) Biology of fishes, 2nd edn. Sanders College Publishings, Fort Worth

Bone Q, Marshal NB, Blaxter JHS (1995) Biology of fishes, 2nd edn. Chapman \& Hall, London

Boxshall GA (1976) The host specificity of Lepeophtheirus pectoralis (Muller, 1776) (Copepoda: Caligidae). J Fish Biol 8:225-264

Bron JE, Sommerville C, Jones M, Rae G (1991) The settlement and attachment of early stages of the salmon louse, Lepeophtheirus salmonis (Copepoda: Caligidae) on the salmon host Salmo salar. J Zool (Lond) 224:201-212

Crisp DJ (1961) Territorial behaviour of barnacle settlement. J Exp Biol 38:429-446

Dogiel VA, Petrushevski GK, Yu I (1958) Parasitology of fishes. Leningrad University Press, Leningrad (translated by Kabata, Z. Oliver \& Boyd, London)

Fowler J, Cohen L (1992) Practical statistics for field biology. John Wiley \& Sons, Chichester

Gravil HR (1996) Studies on the biology and ecology of the free swimming larval stages of Lepeophtheirus salmonis Krøyer, 1838 and Caligus elongatus Nordmann, 1832 (Copepoda: Caligidae). PhD thesis, University of Stirling, Scotland

Gresty KA, Boxshall GA, Nagasawa K (1993) Antennulary sensors of the infective copepodid larva of sea lice (Copepoda: Caligidae). In: Boxshall GA, Defaye D (eds) Pathogens of wild and farmed fish: sea lice. Ellis Horwood, Bodmin, p 83-98

Grimnes A, Jakobsen PJ (1996) The physiological effects of salmon lice infection on post-smolt of Atlantic salmon. J Fish Biol 48:1179-1194

Hanek G, Fernando CH (1978) The role of season, habitat, host age and sex on gill parasites of Lepomis gibbosus (L). Can J Zool 56:1247-1250

Jaworski A, Holm JC (1992) Distribution and structure of the population of sea lice Lepeophtheirus salmonis Krøyer, on Atlantic salmon Salmo salar L. under typical rearing conditions. Aquacult Fish Manag 23: 577-589

Jobling M (1995) Body form, swimming and movement 
through the water. In: Jobung $M$ (ed) Environmental biology of fishes. Fish and fisheries series 16. Chapman \& Hall, London, p 251-295

Johnson SC, Albright LJ (1991) Development, growth and survival of Lepeophtheirus salmonis (Copepoda: Caligidae) under laboratory conditions. J Mar Biol Assoc UK 71: 425-436

Johnson SC, Albright LJ (1992) Comparative susceptibility and histopathology of the response of naïve Atlantic, chinook and coho salmon to experimental infection with Lepeophtheirus salmonis (Copepoda: Caligidae). Dis Aquat Org 14:179-193

Laverack M, Hull MQ (1993) Sensory innervation of the antenna of the pre-adult male Caligus elongatus. In: Boxshall GA, Defaye D (eds) Pathogens of wild and farmed fish: sea lice. Ellis Horwood, Bodmin, p 114-122

Margolis L, Esch GW, Holmes JC, Kuris AM, Schad GA (1982) The use of terms in parasitology. (Report of an ad hoc committee of the American Society of Parasitologists). J Parasitol 68:131-133

Editorial responsibility: Wolfgang Körting,

Hannover, Germany
Sokal RR, Rohlf FJ (1981) Biometry. The principles and practice of statistics in biological research, 2nd edn. WH Freeman \& Co, New York

Tucker CS (1998) Larval settlement and epidemiology of Lepeophtheirus salmonis Krøyer, 1837 (Copepoda; Caligidae). PhD thesis, Institute of Aquaculture, University of Stirling, Scotland

Tucker CS, Sommerville C, Wootten R (2000a) The effects of temperature and salinity on the settlement and survival of copepodids of Lepeophtheirus salmonis (Krøyer, 1837) on Atlantic salmon Salmo salar L. J Fish Dis 23(5):309-320

Tucker CS, Sommerville C, Wootten R (2000b) An investigation into the larval energetics and settlement of the sea louse, Lepeophtheirus salmonis, an ectoparasitic copepod of Atlantic salmon, Salmo salar. Fish Pathology 35: 137-143

Wootten R, Smith JW, Needham EA (1982) Aspects of the biology of the parasitic copepodids Lepeophtheirus salmonis and Caligus elongatus on farmed salmonids, and their treatments. Proc R Soc Edinb Sect B (Biol) 81:185-197

Submitted: June 25, 2001; Accepted: October 24, 2001 Proofs received from author(s): May 6, 2002 